\section{Formula for finding the Date of Easter.}

IT may be of interest to some of your readers to know of the following empirical formula--attributed to the famous mathematician Gauss--for determining in an easy manner the date on which Easter falls in any year from 1900 to 2100 :-

(r) The number of the year is divided by 19 ; remainder $=a$.

(2) The number of the year is divided by 4 ; remainder $=b$

(3) The number of the year is divided by 7 ; remainder $=c$.

(4) $19 \times a+24$ is divided by 30 ; remainder $=d$.

(5) $2 \times b+4 c+6 \times d+5$ is divided by 7 ; remainder $=e$.

Easter will be the $22+d+e$ of March, or, if this number exceed 31 , it will be the $d+e-9$ of April.

The calculation for the present year is as follows:-

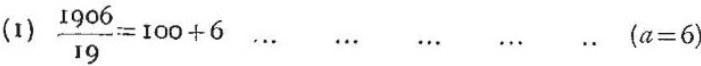

$$
\begin{aligned}
& \text { (2) } \frac{1906}{4}=476+2 \quad \ldots \quad \ldots \quad \ldots \quad \ldots \quad \ldots \quad(b=2) \\
& \text { (3) } \frac{1906}{7}=272+2 \quad \ldots \quad \ldots \quad \ldots \quad \ldots \quad \ldots \quad(c=2) \\
& \text { (4) } \frac{(19 \times 6)+24}{30}=4+18 \quad \ldots \quad \ldots \quad \ldots \quad \ldots \quad(d=18) \\
& \text { (5) } \frac{(2 \times 2)+(4 \times 2)+(6 \times 18)+5}{7}=17+6 \ldots \quad \ldots \quad(e=6)
\end{aligned}
$$

As $22+18+6$ is in excess of $3 I$, we take the alternative $18+6-9=15$, on which day of April Easter falls this year. Chas. Leigh.

The Victoria University of Manchester, March 30.

\section{Chinese Names of Colours.}

IN your issue of January II (p. 246) Mr. Alfred H. Crook writes respecting the name given by the Chinese to a certain tint of blue, which he translates quaintly as "snowgreen colour." The following explanation may be of interest to him and to others of your readers.

Hsïeh, the word he translates "snow," also means " ice," and to the natives of southern China is far better known in reference to the latter object than to the former, as the same name is applied to both natural and artificial ice.

青 Tsing originally meant “clear," “tranquil," " smooth" (applied to water). The change from "smooth water " to the "colour of smooth water" is an easy one, so that a secondary meaning of the word is "sea-green" or "sea-blue." Quite different words are used to express other green tints, such as grass-green, and other blue tints, such as indigo-blue.

Putting the two words together, one finds the meaning of

色青雪 (hsüeh tsing seh) to be “ice-blue colour" or "blue ice colour." Anybody who has noticed the tint of ice in great masses such as one gets in north China and in Switzerland, and who has seen the colour referred to by $\mathrm{Mr}$. Crook, will agree with $m e$ in saying that the name given by the Chinese, far from being fanciful, is very appropriate.

Hong Kong, February 15.

\section{The Adulteration of Butter.}

My attention has been directed to an article in your issue of March $I_{5}$ on "The Adulteration of Butter" in which your contributor refers to the composition of butter fat as a triglyceride of oleic, palmitic, and butyric acids or as containing such a substance. Some years ago i traced this opinion to Mr. Bell, a former analyst of Somerset House, who appears to have based his conclusions upon NO. I9OI, vOL. 737 the insolubility of butter fat in alcohol. Butter fat is, however, soluble in alcohol, and I have no doubt whatever that a process of fractional precipitation from this solution would enable us to ascertain with fair accuracy what the real constituents are. My own experiments certainly pointed to a great number of separate glycerides being present, palmitin and stearin separating out in tolerable purity. The separation of the lower fatty acid compounds is more difficult to attain, probably owing to their existence as esters. It would be interesting to know whether the theory of the presence of triglyceride rests upon a more stable foundation than that of Bell's statement.

Royal Exchange, Manchester, March 17 J. H. Lester.

Your correspondent scarcely does justice to Dr. Bell's observation.

Whether butter fat is completely soluble in alcohol or not depends upon the volume, strength, and temperature of the solvent. Bell showed that when the simple glyceride tributyrin was mixed with melted ordinary fat to the extent of ro per cent., it could be entirely removed by treatment with warm alcohol. But when butter fat was similarly extracted, from 2 per cent. to 3 per cent. only of the fat was dissolved out, and the soluble portion was not tributyrin. Therefore the butyric acid of butter fat is not present as the simple glyceride tributyrin, but chiefly or wholly as a mixed glyceride. Further, the portion dissolved from the butter was found to contain "soluble", and "insoluble" acids in proportions agreeing closely with those required for the mixed glyceride oleo-palmitobutyrin.

Some years later (Proc. Chem. Soc., 1889) Blyth and Robertson noted the isolation from butter fat of a crystalline mixed glyceride, to which they ascribed the formula of palmito-stearo-butyrin.

The "presence of triglyceride" in butter fat will hardly be questioned; what your correspondent has in mind is, apparently, the occurrence of mixed (i.e. complex) glycerides. Many such have been isolated from various natural fats in the last few years; this is, in fact, the most notable feature in the recent chemistry of fats. That complex glycerides exist in butter Bell's and Blyth's experiments leave no reason to doubt, though more rigorous proof of their precise composition is desirable.

March 20.

C. Simmonds.

\section{The Existence of Absolute Motion.}

IN discussing this question it is surely necessary to place stress on the contrast between the places of absolute direction and absolute position in dynamics. The result of observation is that the laws of motion are competent to explain such phenomena as nutation and retain the simple Newtonian form when certain directions which can be found with reasonable accuracy are assumed to be absolute. The contrary assumption, that these directions were not absolute, but moving with absolute angular velocities, say of the order of one degree per second, would necessitate a re-statement of the laws of motion involving great loss of simplicity. In the same way, we cannot without loss of simplicity suppose that the acceleration of the earth with respect to the centre of the solar system differs greatly from the absolute acceleration, and suggest that the material universe has an absolute acceleration of the order of one hundred miles per second per second.

On the other hand, the laws of motion would not be modified in the slightest if the whole universe possessed a uniform and constant absolute velocity, however great that velocity might be, even, for example, ten times the velocity of light. Compared with such a velocity as this, the velocity of the solar system relative to the centroid of the visible stars is probably insignificant. Evidence as to the existence of such a velocity must be sought elsewhere; dynamics alone will not supply it.

Merchant Taylors' School, E.C.
F. J. W. Whipple. 